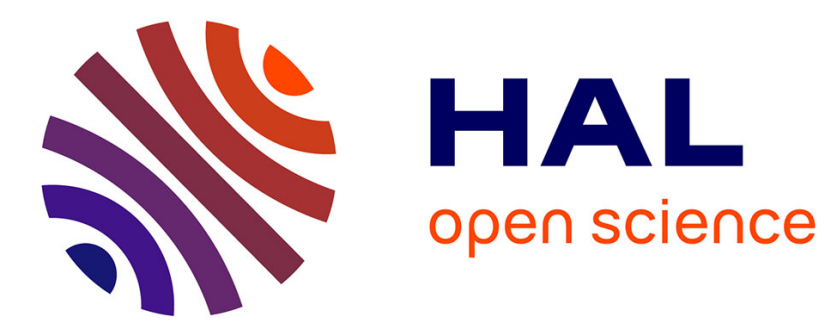

\title{
Effect of one-leg cycling aerobic training in amateur soccer players after anterior cruciate ligament reconstruction.
}

Nicolas Olivier, Thierry Weissland, Serge Berthoin, Renaud Legrand, Jacques Rogez, André Thevenon, Fabrice Prieur

\section{To cite this version:}

Nicolas Olivier, Thierry Weissland, Serge Berthoin, Renaud Legrand, Jacques Rogez, et al.. Effect of one-leg cycling aerobic training in amateur soccer players after anterior cruciate ligament reconstruction.. American journal of physical medicine \& rehabilitation, 2009, American journal of physical medicine \& rehabilitation, 88 (5), pp.362-8. 10.1097/phm.0b013e31819c581f . hal-03434347

\section{HAL Id: hal-03434347 \\ https: / hal.univ-lille.fr/hal-03434347}

Submitted on 18 Nov 2021

HAL is a multi-disciplinary open access archive for the deposit and dissemination of scientific research documents, whether they are published or not. The documents may come from teaching and research institutions in France or abroad, or from public or private research centers.
L'archive ouverte pluridisciplinaire HAL, est destinée au dépôt et à la diffusion de documents scientifiques de niveau recherche, publiés ou non, émanant des établissements d'enseignement et de recherche français ou étrangers, des laboratoires publics ou privés. 
Authors:

Nicolas Olivier, $\mathrm{PhD}$

Thierry Weissland, PhD

Serge Berthoin, PhD

Renaud Legrand, PhD

Jacques Rogez, MD

André Thevenon, MD

Fabrice Prieur, PhD

\section{Affiliations:}

From the Centre de rééducation « Les Hautois $\gg(\mathrm{NO}, \mathrm{JR})$, Oignies, France; Polyclinique de Riaumont (NO, JR), Liévin, France; LEMHEA3608 (NO, SB, RL, AT, FP), Université Lille 2, Ronchin, France; Faculté des Sports et de l'Education Physique (NO, FP), Université d'Artois, Liévin, France; Sportiva (NO), Lesquin, France; Faculté des Sports- EA 3300 (TW), Université de Picardie, Amiens, France; and Centre Hospitalier Régional de Lille (AT), Lille, France.

\section{Correspondence:}

All correspondence and requests for reprints should be addressed to Nicolas Olivier, PhD, Centre de rééducation $\ll$ Les Hautois $\gg$, Nicolas Olivier, Place de la IV république 62590 Oignies, France.

\section{Disclosures:}

None.

0894-9115/09/8805-0362/0 American Journal of Physical Medicine \& Rehabilitation Copyright (C) 2009 by Lippincott Williams \& Wilkins 
B ecause of the current popularity of physical activities and sports, knee trauma is often observed among soccer players of all ages. Specifically, knee injuries related to the anterior cruciate ligament are often reported in soccer players. ${ }^{1}$ Ruptures of the ligament entail a lack of knee stability to perform some movements. To resume sporting activities, surgical reconstruction is generally recommended. This operation inevitably leads to a phase of reduced activity and physical deconditioning. ${ }^{2}$ The consequence of a physiologic deconditioning includes a decrease in work capacity ${ }^{3,4}$ associated with hematologic, ${ }^{5}$ musculoskeletal, ${ }^{6}$ metabolic, ${ }^{6}$ thermoregulatory, ${ }^{7}$ and cardiovascular ${ }^{8}$ impairments. To limit this deconditioning, therapeutic treatment using aerobic exercises performed with healthy limbs, i.e., one leg or two arms, could be offered to the patient. ${ }^{9}$ The maximal cardiorespiratory values are not different between arm cranking or one-leg cycling (OLC).$^{10}$ However, the perceived exertion is lower when the exercises are performed with the lower limb. Thus, after knee-surgery, physiologic and perceptual responses indicate that OLC seemed to be a better adapted method for aerobic reconditioning. ${ }^{10}$

Concerning the OLC training protocols, the literature shows a great heterogeneity in the intensities, frequencies, and durations of the exercise phases generally proposed. ${ }^{11-15}$ It seems that, to obtain significant physiologic adaptations, three weekly sessions are necessary. Programming 30 - to 45-min sessions, with intensities ranging between $70 \%$ and $100 \%$ of peak oxygen uptake $\left(\mathrm{VO}_{2 \text { peak })}\right.$ can generate an improvement of more than $30 \%$ compared with the initial $\mathrm{VO}_{2 \text { peak }}$. The increase in aerobic fitness after OLC training would mainly seem to be due to peripheral vascular adaptations. ${ }^{15,16}$ Indeed, the improvement in maximal oxidative capacity observed during exercise with the trained limb does not seem to be related to an enhanced central cardiac function, but rather to an increased vascularization of the active leg. ${ }^{15,16}$ However, for subjects with a lower aerobic capacity, this kind of training could also generate central adaptations (cardiovascular) and not only peripheral, as observed in active subjects. ${ }^{17}$

To our knowledge, no study has explored the effects of OLC training on the physical recovery of patients in a hospital context. The objective was to assess the beneficial effects induced by an endurance training program during a rehabilitation period. We hypothesized that individualized OLC training during the rehabilitation phase accelerates the cardiorespiratory reconditioning of the patients when compared with standard rehabilitation.

\section{METHODS \\ Subjects}

Twenty-four male regional level soccer players ( $4.7 \pm 0.3 \mathrm{hr} \mathrm{wk}^{-1}$ of physical activities) took part in this study. Their mean age, height, and body mass were $24.2 \pm 3.8$ yrs, $1.80 \pm 0.06 \mathrm{~m}$, and $77.2 \pm 3.9 \mathrm{~kg}$, respectively. They had undergone surgical reconstruction of the anterior cruciate ligament of the knee: central third bone patellar tendon bone autograft (21 subjects) and doubled semitendinosus/doubled gracilis autograft techniques (3 subjects). Between the initial trauma and the surgical operation, all subjects suspended sportsrelated activities for at least $2.0 \pm 0.2$ mos and for this period no standard treatment program was imposed. The study was carried out only with volunteers who had been informed as to the methods, protocol, and procedures used (written and signed consent) and with the agreement of the physicians in charge of rehabilitation. Subjects showing a hemoglobin rate lower than $12 \mathrm{~g} / 100 \mathrm{ml}$ were excluded from the experimentation. The protocol was approved by the Hospital Ethical Committee and complied with the ethical standards of the 1975 Helsinki Declaration.

\section{Experimental Design}

Subjects were randomly divided into 2 groups of 12 subjects by drawing lots. The control group (CG) carried out a rehabilitation program without cardiorespiratory training, whereas the training group (TG) received the rehabilitation program and additional OLC training sessions. Evaluations were carried out before and after rehabilitation at an interval of $6 \mathrm{wks}$. The evaluations were always carried out in the morning, under identical conditions. Both consisted of resting cardiac echography and maximal graded tests with the nonsurgical leg.

\section{Maximal Graded Test}

The one-leg exercise (nonsurgical leg) was performed on a standard bicycle ergometer at a cadence of $65 \mathrm{rev} \mathrm{min}^{-1}$. The only special arrangement for this exercise was to secure the foot on the pedal with a toe clip and an elastic band around the heel. The foot of the nonworking leg was placed on a small chair placed beside the bicycle. The tests began with an imposed power of $55 \mathrm{~W}$ for 2 mins, then the power was increased by $10 \mathrm{~W}$ every 2 mins. ${ }^{18}$ Subjects were the highest possible stage and were encouraged throughout the tests. The exercises were considered maximum if: respiratory exchange ratio was higher than 1.10 and heart rate (HR) reached the theoretical maximum value i.e., when HR was within 10 beats per min (bpm) of the predicted maximal value using the Karvonen's method (age, 220). ${ }^{15}$ All subjects met these criteria. 


\section{Cardiorespiratory Parameter Measurements}

The gas exchange parameters, $\mathrm{VO}_{2}$, carbon dioxide production $\left(\mathrm{VCO}_{2}\right)$, and minute ventilation (VE) were continuously measured in breath-bybreath mode with a cardiopulmonary exercise test system. Before each test, the analyzers were calibrated with two gas mixtures of known concentration. Gas exchange data were averaged every 15 secs. The HR was monitored every 5 secs and data were averaged during 15 secs. Identification of the first (VT1) and second (VT2) ventilatory thresholds were carried out using the methods of Beaver et al. ${ }^{19}$ and Wasserman et al., ${ }^{20}$ respectively. VT1 and VT2 represented ventilatory compensation for increasing metabolic acidosis and was related to perceived effort and performance. ${ }^{19}$ The ventilatory thresholds were expressed in Watts.

\section{Echocardiographic Examination}

Transthoracic echocardiography at rest was carried out with a Sonos 5500 ultrasound system using a $2.5 \mathrm{MHz}$ phased array transducer. It was performed by an experienced cardiologist, who possessed no information on the patients' clinical data. Recordings were taken with the patients in the left lateral decubitus position. Left ventricular end diastolic, and end systolic volumes were measured from the apical four-chamber view using the modified Simpson rule, according to the methodology from the American Society of Echocardiography. ${ }^{21}$ Only representative cycles were measured and the averages of the three best measurements were taken. The endocardial border was traced, excluding the papillary muscles. The frame captured at the $\mathrm{R}$ wave of the electrocardiogram was considered to be the end diastolic frame, and the frame with the smallest left ventricular cavity, the end systolic frame. Stroke volume and ejection fraction at rest were calculated as follows: stroke volume $($ milliliter $)=($ end diastolic volume - end systolic volume), ejection fraction $(\%)=([$ end diastolic volume - end systolic volume]/[end diastolic volume]). Resting HR was measured with a HR monitor. Subjects were placed in the dorsal decubitus position in calm conditions. Measurements were made and averaged during 10 mins after a 10-min quiet period.

\section{Standard Rehabilitation Program}

On the first postoperative day, all patients were encouraged to walk with full weight bearing and full knee extension. The protocol emphasizes restoring full extension and quadriceps function as soon as possible. Progression was based on a 6-wk period, being guided by the presence and degree of pain and swelling. Quadriceps strengthening exer- cises were restricted to closed kinetic chain exercises during the first 2 mos. The key to bridging the gap between rehabilitation and sports application is to return to basic fundamental movement skills. This begins with postural awareness exercises, balance activities, proprioceptive challenges, coordination activities, and basic functional strengthening drills. Patients were allowed to ride an exercise cycle from 5 to 6 wks postoperatively and to begin gymnasium exercises (squats) from 8 wks. ${ }^{22}$

\section{Cardiorespiratory Training Program}

In addition to the classical rehabilitation program, the 12 subjects of the TG benefited from a specific training program with the nonsurgical leg (standard bicycle ergometer). The training program was individualized according to HR and was of an intermittent type, also called interval training. It consisted of several series of exercises alternated with active recovery periods whose intensities were low or moderate. To adapt the protocol to the rehabilitation constraints, the subjects were trained for 21 mins, by alternating 3 mins at $70 \%$ and 3 mins at $85 \%$ of $\mathrm{HR}_{\text {peak }}$. They totaled 18 sessions spread during 6 wks (3 sessions per week). At each training session, a HR monitor was used for HR control and, thus, to check if the intensity of the proposed exercise was well adapted. During the rehabilitation program, the CG carried out five sessions (10 mins per week) with very low intensity $(30 \mathrm{~W})$ to become familiarized with the cranking gesture.

\section{Statistical Analysis}

Data are expressed as means \pm standard deviations. The normality distribution of the data was checked with the Kolmogorov-Smirnov test. A twoway analysis of variance was used to test for an effect or interaction of experimental factors at each time condition. Tukey's post hoc test was used to compare the maximal and submaximal values. The $P<0.05$ level was accepted as significant for all tests.

\section{RESULTS}

In Table 1 the cardiorespiratory data before (T1) and after (T2) rehabilitation are presented. For TG, after the rehabilitation program, peak power output $\left(\mathrm{W}_{\text {peak }}\right) \mathrm{VE}_{\text {peak }}$, VT1, and VT2 values were significantly higher at $\mathrm{T} 2$, when compared with $\mathrm{T} 1$ $(+13 \%,+10 \%,+7 \%$, and $+11 \%$, respectively). For $\mathrm{CG}, \mathrm{W}_{\text {peak }}, \mathrm{VO}_{2 \text { peak }}, \mathrm{VE}_{\text {peak }}$, and VT2 values were significantly lower $(-10 \%,-10 \%,-12 \%$, and $-11 \%$, respectively). At each submaximal power, TG demonstrated significantly lower values for HR (Fig. 1). Conversly, for CG, submaximal values were significantly higher at T2 (Fig. 2). 
TABLE 1 Graded test parameters (mean $\pm \mathrm{SD}$ ) before $(\mathrm{T} 1)$ and after $(\mathrm{T} 2)$ rehabilitation for the control group (CG, $n=12$ ) and the training group (TG, $n=12$ )

\begin{tabular}{llccccc}
\hline & & & & & \\
& $\mathrm{W}_{\text {peak }}, \mathrm{W}$ & $\left(\mathrm{VO}_{\text {2peak }}\right.$ min $\left.^{-1} \mathrm{~kg}^{-1}\right)$ & $\mathrm{VE}_{\text {peak }}, \mathrm{L} \mathrm{min}^{-1}$ & $\mathrm{HR}_{\text {peak }}, \mathrm{bpm}$ & $\mathrm{SV1}, \mathrm{W}$ & $\mathrm{SV2}, \mathrm{W}$ \\
\hline T1 TG & $132 \pm 9$ & $28 \pm 4$ & $83 \pm 17$ & $188 \pm 9$ & $63 \pm 7$ & $86 \pm 9$ \\
T1 CG & $133 \pm 11$ & $29 \pm 4$ & $86 \pm 21$ & $184 \pm 7$ & $69 \pm 5$ & $90 \pm 9$ \\
T2 TG & $152 \pm 9^{a}$ & $30 \pm 5$ & $92 \pm 20^{a}$ & $191 \pm 8$ & $73 \pm 8^{a}$ & $97 \pm 8^{a}$ \\
T2 CG & $120 \pm 10^{a, b}$ & $26 \pm 4^{a, b}$ & $76 \pm 16^{a, b}$ & $185 \pm 5$ & $71 \pm 5$ & $80 \pm 8^{a, b}$
\end{tabular}

${ }^{a}$ Significantly different between $\mathrm{T} 1$ and T2, $P<0.05$.

${ }^{b}$ Significantly different compared with the training group, $P<0.05$.

$\mathrm{W}_{\text {peak }}$, peak power output; $\mathrm{VO}_{2 \text { peak }}$, peak oxygen uptake, $\mathrm{VE}_{\text {peak }}$, peak minute ventilation; $\mathrm{HR}_{\text {peak }}$, peak heart rate; SV1, first ventilatory threshold; SV2, second ventilatory threshold.

The averaged variations in resting cardiac parameters measured with echocardiography are presented in Table 2 . For CG, a significant reduction in end diastolic volume (T1, $116 \pm 17 \mathrm{ml}$; T2, $97 \pm 16 \mathrm{ml} ; P<0.05)$ and stroke volume (T1, $75 \pm$ $14 \mathrm{ml} ; \mathrm{T} 2,59 \pm 12 \mathrm{ml} ; P<0.05)$ were observed at T2. The resting HR was significantly higher (T1, $69 \pm 11$ bpm; T2, $76 \pm 13$ bpm, $P<0.05)$. For TG, the cardiac parameters were similar between $\mathrm{T} 1$ and $\mathrm{T} 2$.

\section{DISCUSSION}

The objective of this study was to examine cardiorespiratory fitness changes in subjects having undergone anterior cruciate ligament reconstruction and to assess the benefits of an OLC aerobic training program performed during the rehabilitation period.

\section{TG: Rehabilitation Program and OLC Training}

After rehabilitation, at each submaximal power, TG demonstrated significantly lower values for HR (Fig. 1) and both the first and second VT appeared at higher absolute power output values. These data are in agreement with the results of the literature. ${ }^{12-14}$ At maximal intensities, $\mathrm{W}_{\text {peak }}$ was $13 \%$ higher and $\mathrm{VE}_{\text {peak }} 11 \%$ higher after the OLC training. Contrary to some authors ${ }^{12,15,23}$ who reported a significant increase in $\mathrm{VO}_{2 \text { peak }}$ after OLC training $(+14 \%-33 \%)$, we failed to observe a significant increase in $\mathrm{VO}_{2 \text { peak }}$ after the training program (T1, $28 \pm 4$ vs. T2, $30 \pm 5 \mathrm{ml} \mathrm{min}^{-1} \mathrm{~kg}^{-1}$; not significant). The studies that showed an increased aerobic fitness by means of OLC exercises proposed a 2 -mo training program with 30 - to 45 -min sessions..$^{8,11,13,23}$ In a rehabilitation context, training is much shorter and corresponds to the patient's time of hospitalization and to his health status. Because of the specific multifield nature of the care, made up of physical therapy and physical training, the sessions were adapted by necessity. This element could explain the unchanged values of $\mathrm{VO}_{2 \text { peak }}$ in the present study.

OLC could involve specific adaptations, which would be peripheral rather than central. ${ }^{15,16}$ Indeed, the increase in the maximal oxidative poten-

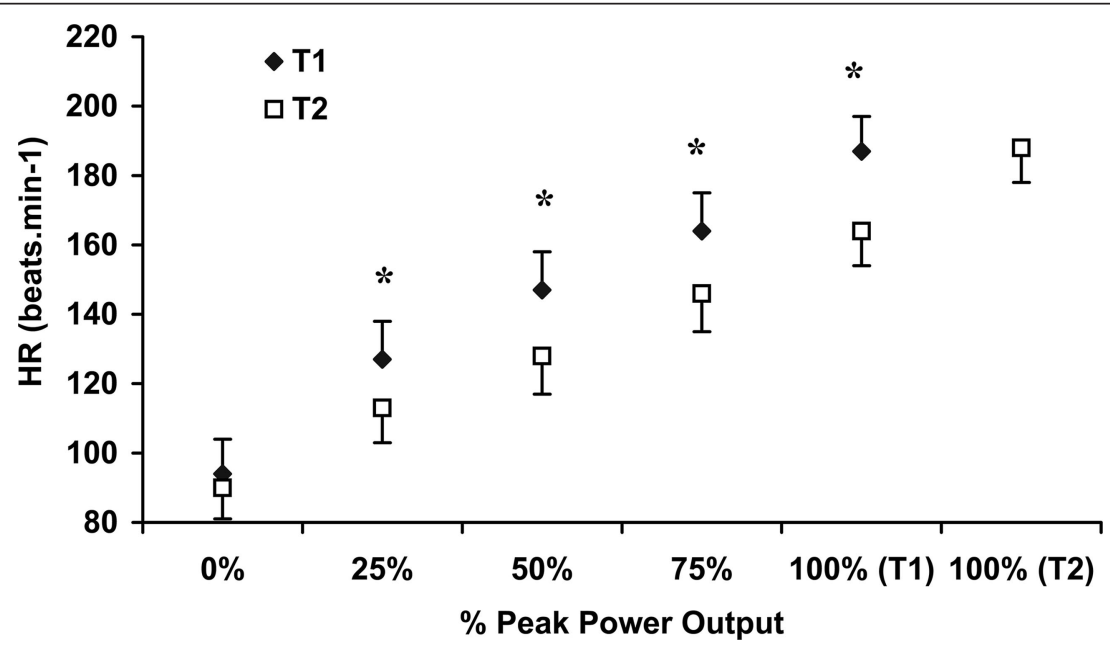

FIGURE 1 Heart rate (HR) values (mean $\pm S D$ ) of TG recorded at each stage of the graded test, before (T1) and after rehabilitation (T2). HR data were compared at 25\%,50\%,75\%, and $100 \%$ of $W_{\text {peak }}$ at T1. 


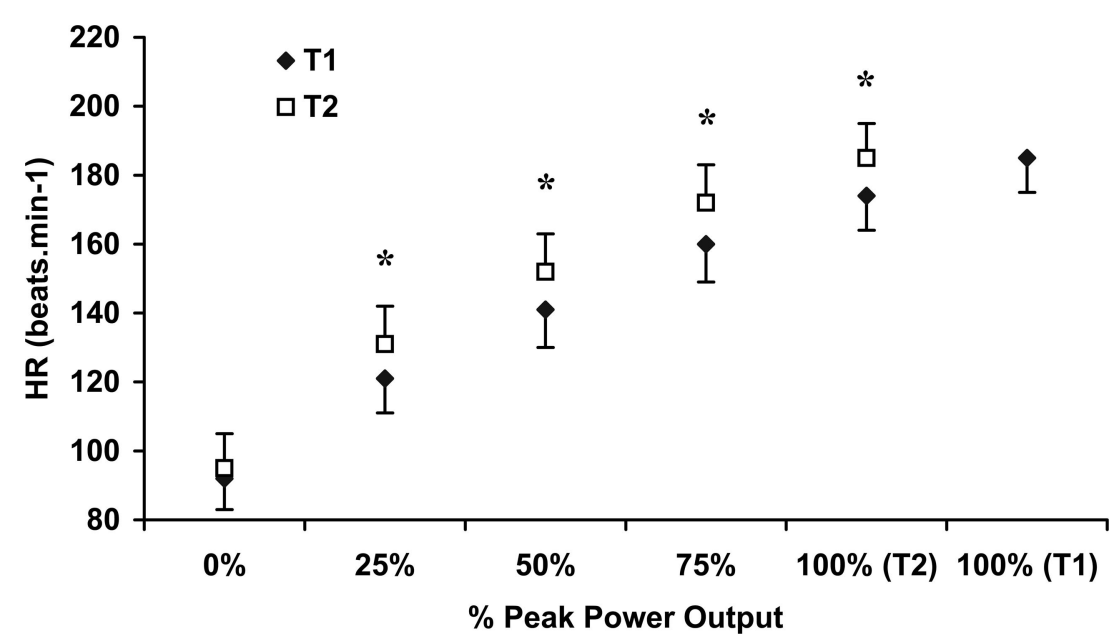

FIGURE 2 Heart rate (HR) values (mean $\pm S D$ ) of CG recorded at each stage of the graded test, before (T1) and after rehabilitation (T2). HR data were compared at 25\%, 50\%, 75\%, and $100 \%$ of $W_{\text {peak }}$ at $\mathrm{T} 1$.

tial when training with a small muscular group could be mainly due to an improvement in the vascularization of active tissue. ${ }^{15}$ After several weeks of OLC training, the increase in capillarization would be possible, allowing an increase in maximal muscle blood flow. ${ }^{24}$ Our program was probably not sufficient to induce an increase in maximal cardiac output. Similar values of cardiac parameters at rest in TG (Table 2) support this assumption. With longer protocol durations, some authors recorded higher maximal cardiac output after OLC training. ${ }^{13,15}$ Nevertheless, the lack of change in the left ventricular dimensions, mass, and performance (index of contractility) after the OLC training suggested that intrinsic cardiac adaptations are not necessary to achieve such an increase in maximal cardiac output. ${ }^{15}$ An increase in the venous return could induce modification of cardiac output. ${ }^{13,14}$

Even though our results testify to a significant improvement of the respiratory function, this must be taken with caution. Knowing that performance increase is not only due to a metabolic improvement, but also to gesture effectiveness, the subjects during the training period organized in an eco- nomic process; this strategy could explain partly the increase in $\mathrm{W}_{\text {peak }}(+13 \%)$. Nevertheless, OLC seems to be an effective means to limit deconditioning. More especially, this training does not seem to worsen the muscular recovery of the injured limb. At 4-mo postsurgery, the isokinetic performance of knee extensor muscles of the injured leg was significantly lower as compared with that of the healthy leg (peak torque at 90 degrees/ sec, $-26 \%$; power at 180 degrees/sec, $-14 \%$; total work at 240 degrees/sec, $-19 \%$ ), but this deficit was identical for the two groups.

\section{CG: Rehabilitation Program Without Cardiorespiratory Training}

After 6 wks of rehabilitation without an aerobic training program, a fast and significant $(P<0.05)$ reduction in aerobic fitness was observed: a $10 \%$ drop in $\mathrm{VO}_{2 \text { peak }}$ and a $10 \%$ drop in $\mathrm{W}_{\text {peak }}$. The first and second VT appeared at lower absolute power output values testifying to a reduction in aerobic fitness (Table 1). At rest and submaximal intensities, HR values were higher (Table 1 and Fig. 2). Some authors have suggested that the higher HR observed after prolonged confinement could mainly

TABLE 2 Cardiac parameters, before (T1) and after (T2) rehabilitation for control group (CG, $\mathrm{n}=$ 12) and training group (TG, $n=12)$

\begin{tabular}{lcllll}
\hline & EDV, $\mathrm{ml}$ & ESV, ml & SV, ml & EF, \% & HR, bpm \\
\hline T1 TG & $110 \pm 14$ & $42 \pm 8$ & $68 \pm 13$ & $62 \pm 8$ & $73 \pm 8$ \\
T1 CG & $116 \pm 17$ & $41 \pm 11$ & $75 \pm 14$ & $65 \pm 9$ & $69 \pm 11$ \\
T2 TG & $108 \pm 12$ & $40 \pm 10$ & $68 \pm 12$ & $63 \pm 7$ & $75 \pm 9$ \\
T2 CG & $97 \pm 16^{a}$ & $38 \pm 11$ & $59 \pm 12^{a, b}$ & $61 \pm 5$ & $76 \pm 13^{a}$ \\
\hline
\end{tabular}

${ }^{a}$ Significantly different between T1 and T2; $P<0.05$.

${ }^{b}$ Significantly different compared with training group, $P<0.05$.

EDV, end diastolic volume; ESV, end systolic volume; SV, stroke volume; EF, ejection fraction; HR, heart rate at rest. 
result from a reduction in stroke volume and cardiac vagal activity. ${ }^{7}$ Our data are not easily comparable with those of the literature because, to our knowledge, no study has treated the effect of a hospitalization on the deconditioning fitness under real conditions. The protocol ${ }^{13,15,23}$ only partially reflects the reality of anterior cruciate ligament reconstruction.

The reduction in aerobic fitness could be explained by an alteration in cardiovascular function. In soccer players, 7 days of hospitalization due to knee surgery led to resting cardiac deconditioning characterized by a significant reduction in the stroke volume. ${ }^{25}$ During the 6 wks of hospitalization without an aerobic training program, the physical deconditioning continued (Table 2). The decrease in blood volume ${ }^{3,5}$ is largely responsible for the observed alteration in cardiovascular function during periods of inactivity. After such periods, the reduced blood volume has been associated with reduced plasma volume and venous return. ${ }^{4}$ Many studies have demonstrated that $\sim 70 \%$ of the alteration in $\mathrm{VO}_{2 \max }$ can be explained by a decrease in plasma volume. ${ }^{8,25}$ This assumption was confirmed by the data of echocardiographic measurements (Table 2). In the present study, 6 wks of rehabilitation without an aerobic training program led to a significant $(P<0.05) 21 \%$ reduction in stroke volume. As explained by Starling's law, ${ }^{26}$ the stroke volume is dependent on the degree of stretch of the ventricular walls.

It would seem that the progressive resumption of walking, quadriceps strengthening exercises, and various techniques suggested during rehabilitation ${ }^{27}$ would have little effect on the process of reconditioning subjects. To preserve the benefit of training, Hickson et al. ${ }^{28}$ suggested that the intensity of the exercise phases should be around $70 \%$ of $\mathrm{VO}_{2 \text { peak }}$ with at least three sessions per week. These results suggest that the aerobic program during the rehabilitation phase was essential for recovering. However, movement using crutches requires higher energy expenditure than normal walking. ${ }^{29}$ It could not constitute a sufficient exercise to allow the initial aerobic fitness level to be restored. Comparatively with TG, the control subjects had lower values and were behind with their physical condition, to resume sporting activity. Therefore, although aware of their deficits, soccer players who are eager to regain their place in their soccer teams as fast as possible are likely to not to respect the therapist's instructions, thus increasing recurrence.

\section{CONCLUSION}

In soccer players, 6 weeks of hospitalization due to anterior cruciate ligament reconstruction led to resting cardiac deconditioning characterized by a significant reduction in stroke volume. With- out cardiorespiratory training, a fast and significant reduction in aerobic fitness was observed. OLC seems to be an effective means to limit deconditioning. These elements should encourage the hospital practitioner to propose a program of aerobic training involving the healthy limbs in addition to conventional rehabilitation.

\section{REFERENCES}

1. Luthje P, Nurmi I, Kataja M, et al: Epidemiology and traumatology of injuries in elite soccer: A prospective study in Finland. Scan J Med Sci Sports 1986; $6: 180-5$

2. Olivier N, Legrand R, Rogez J, et al: Effects of knee surgery on cardiac function in soccer players. Am J Phys Med Rehabil 2007;86:45-9

3. Mujika I: Detraining: Loss of training-induced physiological and performance adaptations. I. Short-term insufficient training stimulus. Sports Med 2000;30: $79-87$

4. Bassey EJ, Bennet T, Birmingham AT, et al: Effects of surgical operation and bed rest on cardiovascular responses to exercise in hospital patients. J Physiol 1973;7:588-92

5. Convertino VA: Effects of exercise and inactivity on intravascular volume and cardiovascular control mechanisms. Acta Astronautico 1992;27:123-9

6. Mujika I, Padilla S: Cardiorespiratory and metabolic characteristic of detraining in humans. Med Sci Sports Exerc 2000;33:413-21

7. Crandall CG, Engelke KA, Pawelczyk JA, et al: Power spectral and time based analysis of heart rate variability following 15 days head down bed rest. Aviat Space Environ Med 1994;65:1105-9

8. Convertino VA. Effects of exercise and inactivity on intravascular, in: Scandler $\mathrm{H}$, Vernikos-Danellis $\mathrm{J}$ (eds): Inactivity: Physiological Effects. Orlando, FL: Academic Press, 1986, pp 149-91

9. Toner MM, Sawka MN, Levine L, et al: Cardiorespiratory responses to exercise distributed between the upper and the lower body. J Appl Physiol 1985;54: 1403-7

10. Olivier N, Legrand R, Rogez J, et al: One-leg cycling versus arm cranking: Which one is the most appropriate for physical reconditioning after knee surgery? Arch Phys Med Rehabil 2008;89:508-12

11. Chin T, Sawamura S, Fujita H, et al: Effect of endurance training program based on anaerobic threshold (AT) for lower limb amputees. J Rehabil Res Dev 2001;38:7-11

12. Davies CT, Sargeant AJ: Effects of training on the physiological responses to one-and two-leg work. J Appl Physiol 1975;38:377-85

13. Klausen K, Secher NH, Clausen JP, et al: Central and regional circulatory adaptations to one-leg training. J Appl Physiol 1982;52:976-83

14. Ray CA: Sympathetic adaptations to one legged training. J Appl Physiol 1999;86:1583-7 
15. Thomas SG, Cunningham DA, Plyley MJ, et al: Central and peripheral adaptations of the gas transport system to one leg training. Can J Physiol Pharmacol 1981;59:1146-54

16. Clausen JP: Effect of physical training on cardiovascular adjustments to exercise in man. Physiol Rev 1977;57:779-815

17. Dolmage TE, Goldstein RS: Response to one-legged cycling in patients with COPD. Chest 2006;129: 325-32

18. Neary PJ, Wenger HA: The effects of one and two legged exercise on the lactate and ventilatory threshold. Eur J Appl Physiol 1986;54:591-5

19. Beaver WL, Wasserman K, Whipp BJ: A new method for detecting anaerobic threshold by gas exchange. J Appl Physiol 1986;60:2020-7

20. Wasserman K, Whipp BJ, Koyal SN, et al: Anaerobic threshold and respiratory gas exchange during exercise. J Appl Physiol 1973;35:36-45

21. Schiller MD, Shah PM, Crawford M, et al: Recommendations for quantitation of the left ventricle by two-dimensional echocardiography. American Society of Echocardiography Committee on Standards, Subcommittee on Quantitation of Two-Dimensional Echocardiograms. J Am Soc Echocardiogr 1989;2:358-67

22. Middleton P, Trouvé P, Puig P: Prise en charge du sportif de haut niveau après chirurgie ligamentaire du LCA. J Traumatol Sport 1997;14:98-102

23. Saltin B, Nazar K, Costill DL, et al: The nature of the training response; peripheral and central adaptations of one-legged exercise. Acta Physiol Scand 1976;96:289-305

24. Andersen P, Henriksson J: Capillary supply of the quadriceps femoris muscle of man: adaptive response to exercise. J Physiol 1977;270:677-90

25. Coyle EF, Hemmert MK, Coggan AR: Effects of detraining on cardiovascular response to exercise: Role of blood volume. J Appl Physiol 1986;60:95-9

26. Glower DD, Spartt MD, Snow ND: Linear of the franck-starling relationship in the intact heart: the concept of preoload recruitable stroke work. Circulation 1985;71:994-1009

27. Fisher D, Tewes D, Boyd J, et al: Home based rehabilitation for anterior cruciate ligament reconstruction. Clin Orthop 1998;347:194-9

28. Hickson RC, Foster C, Pollock ML, Galassi TM, et al: Reduced training intensities and loss of aerobic power, endurance, and cardiac growth. J Appl Physiol 1985;58:492-9

29. Waters RL, Mulroy S: The energy expenditure of normal and pathologic gait. Gait Posture 1999;9: 207-31 